\title{
A New System for Steam Boiler Tubes using Artificial Neural Network
}

\author{
Gurusamy Pandian, A.Akhtar Kalam
}

\begin{abstract}
A major inspection challenge facing the boiler industries is to satisfy the welds in tubing and plate during the manufacturing, erection and commissioning stages. During commercial operation the plant boiler tubes that leaks due to downtime. As the main part of the boiler, the water wall tube which runs on dangerous environment may lead to serious boiler accidents, causing of the tubes failure. For this reason, inspecting the defects on the steam boiler tube comprehensively is extremely required. However, single traditional NDT inspection method is limited .In terms of the ability of identifying different kinds of defects. In order to meet the requirement of fullscale inspection, in this paper, a new system foe steam boiler tubes are experimented. After experiment, the new system can effectively measure the remaining wall thickness and identify different kinds of defects including pinholes and circumferential cracks with the sensor being moved outside the tubes using artificial neural networks.
\end{abstract}

Keywords - water wall tubes; combination; NDT inspection method, Artificial Neural Networks

\section{INTRODUCTION}

The boiler is a crucial energy-conversion device. Because the main a part of the boiler, water wall tubes that carries with it multiple tubes connected by rip plates [1] run on risky setting. Corrosion, erosion and fatigue cause the failure of water wall tubes. A lot of boiler seriously could cause the boiler accident [2]. So as to unravel this downside, inspecting the defects on tubes comprehensively is much needed. The defects of water wall tubes are often inspected by ancient NDT ways, like electricity supersonic testing (PUT), magnetic flux outflow (MFL), magnetism acoustic electrical device (EMAT) and eddy current (EC) [3]. However, of these NDT examination ways have their limitations severally (see table 1). Obviously, single ancient NDT examination technique is tough to satisfy the wants of fully-testing, therefore combining 2 or a lot of completely different sorts of NDT ways in one detection system is extraordinarily needed. During this method, the benefits of various ways are often integrated.

Through comparison, combining MFL associated EMAT ways is an effectively thanks to determine common defects on the surface of water wall tubes, as well as pinholes, circumferential cracks and cutting of wall thickness. In concerning to the matter regarding desegregation EMAT and MFL ways for the pipeline detection, Song X. C. et al. designed a water wall tubes examination system. During this system, ultrasound is worked up by the vertical field [4].

Revised Manuscript Received on December 5, 2019

* Correspondence Author

PG.Gurusamy Pandian, Kalasalingam Academy of Research and Education, Krishnankoil, India.profpggp@gmail.com

A.Akhtar Kalam, School of Engineering and Science Victoria University, Melbourne,Australia. akhtarkalam@vu.edu.au
However, this type of EMAT operating technique could cause the subsequent problems: first of all, there'll be an exact quantity of longitudinal wave officious the thickness measurement; second, the EMAT coil placed magnetization of the specimen are going to be weaker; third, there'll be associate echo from permanent magnets or pole shoes worrying the wall thickness detection[5].

In order to unravel these issues, during this paper, a brand new system is going to be introduced, that employing a combination of EMAT and MFL. During this new system, EMAT takes ad- vantage of the horizontal field used for MFL detection to excite the ultrasound. Below this circum- stance, the excitation mechanism of the EMAT is different from the overall mechanism that's in the main supported the Lorentz-force [6].

\section{MEASUREMENT PRINCIPLE}

The principle of the new system is predicated on the magnetism acoustic technology (EMAT) and also the magnetic flux outflow (MFL) technology. The sensing element of the system is shown in figure one, which has a magnetic bar (magnetic yoke, a pair of permanent magnets and a couple of pole shoes) and a combi sensing element (EMAT coils and MFL sensors). The combi sensing element is found within the center of the magnetic bar.

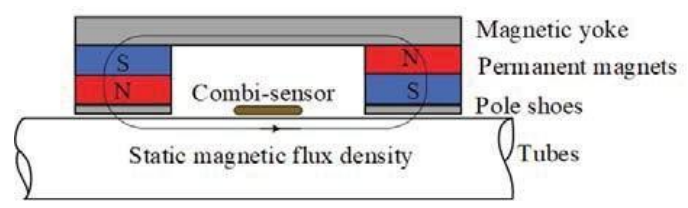

Fig1: defining Static magnetic flux density

As way as EMAT coils area unit involved, each coil consists of a transmitter coil and a receiver coil. Polarized supersonic shear waves area unit generated supported the magnetic constrictive impact. In general, the excitation mechanisms of the electro-magnetic supersonic testing technique embrace Lorentz-force, magnetization and magnetostriction-force mechanism. once the tube is attractable a horizontal field, force and magnetization force area unit virtually equal in size and opposite in direction, in order that polarized supersonic shear waves in magnetism materials would be generated in the main betting on magneto striction impact [7]. As shown in figure a pair of. The supersonic pulses propagate sheer to the pipe wall surface. From the time-of-flight of the back-wall echo and also the well-known supersonic rate in pipe steel, the remaining wall thick- capes are often obtained [8]. 


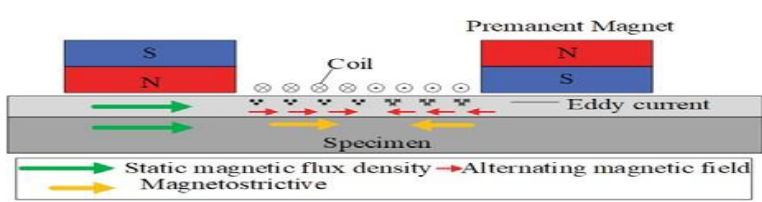

Fig2. The excitation mechanisms of EMAT under the horizontal magnetic field

Based on the testing principle of MFL, the horizontal field that is employed for EMAT also can be used for MFL detection. Once the specimen has defects, there'll be stray-flux field distributed on the outer surface round the defects, which might be picked up by MFL sensors for examination.

\section{SENSOR DESIGN}

\section{A. Choosing the appropriate operating point}

The first step for sensing element coming up with is selecting the appropriate in operation purpose. In reference to the EMAT, the amplitude of the back wall echo depends powerfully on the strength of the horizontal field. For various pipeline steels, this dependence follows the However; attributable to the very fact that thickness reduction in tube wall ends up in the rise

Limit dead the region of thirty to thirty five $\mathrm{kA} / \mathrm{m}$. magnetic bias field at those position, so as to form certain the amplitude of the supersonic back- wall echo being sufficient not solely within the space with defects however while not defects, the operation purpose ought to be chosen to regarding $3 / 4$ of the utmost amplitude within the raising a part of the curve, from $20 \mathrm{kA} / \mathrm{m}$ to twenty five $20 \mathrm{kA} / \mathrm{m}$ [9].In regard to the appropriate MFL operation point, the amplitude of the hall sensor signal depends on not only In general, the thanks to decide if the fabric is closed to saturation is that once the field strength in- crease regarding 100 percent, the magnetic strength solely increases regarding I Chronicles. According the saturation curve of it, the simplest vary of the in operation purpose is between a pair of. $5 \mathrm{kA} / \mathrm{m}$ and eight $\mathrm{kA} / \mathrm{m}$.

\section{B.Designing the structure of the Combo-sensor}

The static magnetic field used for detection is mainly supplied by the magnetic bar. In order to not only make sure the appropriate operating point of EMAT and MFL technology, but also minimize the magnetic bar as much as possible, the Comsol software is used for simulation design. By using the control variable method, the final size of the different part of the magnetic bar is shown in table 2 .

After the magnetic bar is completed, so as to deter- mine the simplest location for coils and hall sensors (MFL sensor), the horizontal field strength within the tube wall ought to be measured. Use the gauss meter to live the field strength (B), in line with the interfac- ing conditions, to estimate magnetic strength $(\mathrm{H})$ within the wall of the tube. In reference to the fabric properties of the tube, the magnitude the ratio of $\mathrm{H} / \mathrm{B}$ is about 1000 .

The magnetic strength distribution between the pole shoes is shown as figure 4.It are often seen that the simplest location for EMAT coils is space $\mathrm{B}$, the magnetic strength is between $20 \mathrm{kA} / \mathrm{m}$ and twenty five $\mathrm{kA} / \mathrm{m}$. The hall sensors are going to be settled within the space A, the field strength is or so five $.5 \mathrm{kA} / \mathrm{m}$.

The final structure of the sensing element is shown in figure five. 3 EMAT coils area unit organized closely on the circumference of the tube. Sixteen hall sensors area unit used as MFL sensors to discover the scale of the outflow field in a pair of directions (axial and radial) severally. Channel one to channel eight is employed to discover the radial field and also the channel nine to channel sixteen is employed for axial field detection.

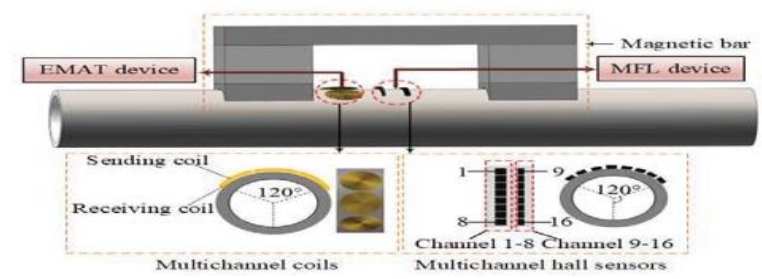

Fig 3. Designing the structure of the Combi-sensor The static magnetic field used for detection is mainly

\section{C.Water Wall Tube Inspection Devices}

The EMAT moveable device, ETG-100 from Lingsheng Technology Co. Ltd, is chosen to live the tube wall thickness[12].The device will scan the thickness within the vary between one. $5 \mathrm{~mm}$ to $500 \mathrm{~mm}$, through cooperating with DE EMAT sensing element, the exactness is zero. $01 \mathrm{~mm}$. The MFL device is especially wont to method the signal from the multiple hall sensors. The device includes sever- al completely different circuit components, as shown in figure six [10].

Different circuit's area unit won't to attain completely different functions. The outflow field signals from the hall sensors are going to be 1 st sent into the signal process circuit, experiencing process as well as filtering the high frequency components in it and amplifying the remainder components. The signal is going to be then born-again into digital one, before being sent to the small controller. Together with the computer code, the detection knowledge are often saved in TF card or translated to the USB flash driver. And also the wave of each hall sensing element are often shown on the screen severally or at identical time[11].

\section{EXPERIMENT}

In order to validate the performance of the new system that employing a combination of EMAT and MFL, a 20\# steel tube was created as specimen containing three artificial defects, the scale of the defects is shown in table three. The tube wall thickness is regarding six millimeter. However, during this system, the mensuration results of EMAT and MFL area unit still freelance, later, the results ought to be integrated, so as to show complete tube wall info directly. It are often seen by analyzing the experimental results 1) As way as EMAT section thinks about, the EMAT potable device will live the wall thickness effectively

2) As way as MFL section thinks about, 3 artificial defects are often detected effectively. 
3 ) In reference to the defect one and defect a pair of, that area unit each pinholes. 2 defects have identical radius and also the defects one is deeper than defects a pair of. At now, the dimension of the outflow field signal is same, however, the peak-to-peak price of the signal in a pair of directions (radial and axial) is completely different, and that is proportional to the depth

The fact is that the new system will discover the entire leakage signal on the detection line through the experiment. So as to use the restricted MFL signal knowledge mapping the define of the defects; the interpolation ought to be applied to complete the info. Figure nine shows two-dimensional imaging results of the full outflow field higher than the specimen, that desegregation the outflow field component in 2 directions (axial and radial). It are often seen that the imaging results of the pinholes deviates from its actual form, attributable to the impact of stray-flux on the field of defect-free space round the defect. So as to use the outflow field to reconstruct the defect, some signal process algorithms ought to be ap- plied to the signal. Besides this, from this two- dimensional imaging result, the position relationship of the 3 defects is often comparatively accurately determined at intervals the allowable vary of error.

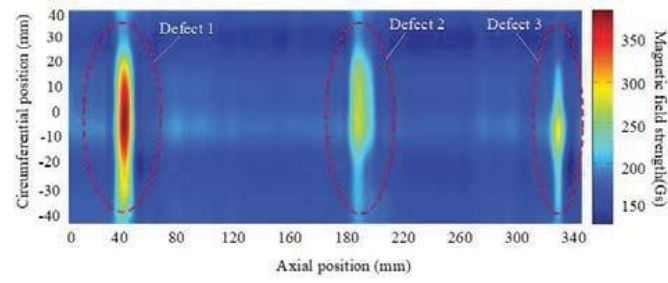

Fig 4. Axial position

\section{CONCLUSION}

In order to make sure reliable mensuration for various reasonably defects on the water wall tubes, during this paper, a brand new system is intended employing a combination of EMAT and MFL technologies. During this new system, EMAT takes advantage of the horizontal field used for MFL detection to excite the ultrasound. In reference to the sensing element. Designing, the simplest location for EMAT coils is within the space that the field strength is between $20 \mathrm{kA} / \mathrm{m}$ and twenty five $\mathrm{kA} / \mathrm{m}$. the simplest location for hall sensors is within the space that the field strength is or so five. $5 \mathrm{kA} / \mathrm{m}$. Build the experimental platform, the results of the experiment show that the system will live the remaining wall thickness accurately and determine all the unreal defects as well as a pair of pinholes (the radius is $3 \mathrm{~mm}$, the depth $3 \mathrm{~mm}$ and $6 \mathrm{~mm}$ respectively) and a circumferential crack (the dimension is $1 \mathrm{~mm}$ and also the depth is $3 \mathrm{~mm}$ ). Through desegregation the outflow field part in 2 directions (radial and axial) and mapping the define of the defects, the position of the 3 defects are often comparatively accurately determined at intervals the allowable vary of error.

Furthermore, as for all the pipeline examination equipment as well as the MFL sensing element, the sensing element half are often replaced by the combi-sensor, during which method, not solely the defects however conjointly the wall thickness info are often obtained.

\section{REFERENCES}

[1]A. Boonyaprapasorn, T. Maneewarn, and K. Thung-Od, "A prototype of inspection robot for water wall tubes in boiler," Proc. 3rd Int. Conf. Appl. Robot. Power Ind. CARPI 2014, no. 55, 2015.

[2]X. Lu, G. Liu, and S. Luan, "The development of the boiler water wall tube inspection," 3rd Int. Conf. Deregul. Restruct. Power Technol. DRPT 2008, no. April, pp. 2415-2420, 2008.

[3]H Su Guoping, Wang Zhiguo, Zhou Hongguang, et al., Numerical simulation on evaporation and heat transfer characteristics of seawater in corrugated plateevaporator, Therm. Power Generat. 9 (2017) 83-91.

[4] T.M.A. Elmaaty, A.E. Kabeel, M. Mahgoub, Corrugated plate heat exchanger review, Renew. Sustain. Energy Rev. 70 (2017) 852-860.

[5] P.P. Psyllaki, G. Pantazopoulos, A. Pistoli, Degradation of stainless steel grids in chemically aggressive environment, Eng. Fail. Anal. 35 (2013) 418-426.

[6] U.K. Mudali, M.G. Pujar, 3 - Pitting corrosion of austenitic stainless steels and their weldments, in: H.S. Khatak, B. Raj (Eds.), Corrosion of Austenitic StainlessSteels, Woodhead Publishing, 2002, pp. 74-105.Z.D. F

[7]J. Park, J.-W. Kim, J. Kim, and S. Park, “A study on MFL based wire rope damage detection," no. April 2017, p. 101681H, 2017

[8]J. Wu, H. Fang,X.HuangH. Xia, Y. Kang, and C. Tang, "An Online MFL Sensing Method for Steel Pipe Based on the Magnetic Guiding Effect," Sensors, vol. 17, no. 12, p. 2911, 2017.

[9]F. Niese, A. Yashan, and H. Willems, "Wall thickness measurement sensor for pipeline inspection using EMAT technology in combination with pulsed eddy current and MFL," Non-destructive testing, Aust., vol 3, no. 45, pp. 84-87, 2008.

[10]. Lazarev, "Numericalstudy on capabilities constructions of electromagnetic acoustic transducers (EMAT) with permanent magnets for inline inspection of pipeline 6"," no. 2016, pp. 0936-0939, 2016.

[11]H. Boughedda, T. Hacib, M. Chelabi, H. Acikgoz, and Y. Le Bihan, "Electromagnetic Acoustic Transducer for

\section{AUTHORS PROFILE}

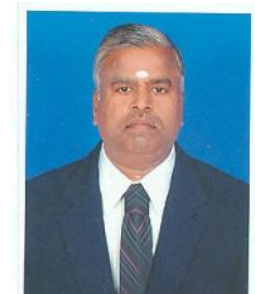

PG.Gurusamypandian., was born at Chatrapatti, India in 1957. He graduated in Automobile Engineering from MIT Madras and post graduated in Manufacturing Engineering from Prist University, Tanjore, India. He has done his Ph.D (Safety Engineering) in 2016 from Kalasalingam Academy of Research and Education, Krishnankoil. Now he is currently working as Associate Professor in the Department of Automobile Engineering, Kalasalingam Academy of Research and Education. He has published 10 International Journals, 10 papers in International Level Conferences and 25 National level Conferences. His research interests in Safety and Textile sectors. 